\title{
Inflammatory Myopathy and Walker-Warburg Syndrome: Etiologic Implications
}

\author{
Michael I. Shevell, Bernard Rosenblatt and Kenneth Silver
}

\begin{abstract}
Walker-Warburg syndrome is a well delineated clinical entity with characteristic brain and eye anomalies. Recent diagnostic surveys have revealed that muscular dystrophy is an obligatory feature of this syndome. We report a patient with an inflammatory myopathy that preceded dystrophic changes. While reports of parental consanguinity and multiple affected sibships strongly suggest an autosomal recessive genetic basis for this syndrome, previous pathological analyses of the CNS have suggested an inflammatory process. Our case supports both the notion of an aberrant inflammatory process that is likely under genetic control or etiologic heterogeneity (phenocopies) underlying this syndrome.
\end{abstract}

RÉSUMÉ: Myopathie inflammatoire et syndrome de Walker-Warburg: considérations étiologiques. Le syndrome de Walker-Warburg est une entité clinique bien définie, avec des anomalies cérébrales et oculaires caractéristiques. Des études récentes des critères diagnostiques ont montré que la dystophie musculaire est une manifestation obligatoire de ce syndrome. Nous rapportons le cas d'un patient présentant des manifestations de myopathie inflammatoire qui ont précédé les changements dystrophiques. Bien que certaines descriptions de cas font état de consanguinité entre les parents et de fratries ayant plusieurs cas atteints, suggérant que ce syndrome a une étiologie génétique autosomale récessive, des études anatomopathologiques du système nerveux central indiquent qu'il peut s'agir d'un processus inflammatoire. Le cas que nous présentons appuie le concept qu'il existe un processus inflammatoire aberrant, vraisemblablement sous contrôle génétique, ou une hétérogénéité étiologique (phénocopies) sous-jacente à ce syndrome.

Can. J. Neurol. Sci. 1993; 20:227-229

Despite a plethora of often bewildering eponyms, including Walker's lissencephaly,' Warburg syndrome, ${ }^{2-4}$ HARD +/- E syndrome (hydrocephalus, agyria, retinal dyplasia, encephalocele $]^{5-8}$ cerebro-ocular dysgenesis, ${ }^{9}$ muscle-eye-brain (MEB) disease, ${ }^{(1)-12}$ cerebro-ocular dysplasia-muscular dystrophy (COD-MD) syndrome ${ }^{13.14}$ and cerebro-oculo-muscular (COM) syndrome, ${ }^{15.16}$ it has become apparent that these entities are synonymous with Walker-Warburg syndrome. ${ }^{17}$ Originally conceptualized as an autosomal recessive disorder with characteristic brain and eye abnormalities, ${ }^{18}$ the most recent diagnostic criteria ${ }^{17}$ emphasize four obligatory elements; type II lissencephaly (widespread agyria with severely disorganized cortex without recognizable layers), cerebellar malformation, retinal malformation and muscle pathology in the form of a congenital muscular dystrophy. Present theories of pathogenesis have emphasized a genetic etiology, ${ }^{17}$ however some authors have been impressed by pathologic evidence for chronic inflammatory changes in the central nervous system. ${ }^{1.9}$ We wish to report a case of WalkerWarburg syndrome with an inflammatory myopathy that antedates dystrophic changes and consider the etiologic implications of this finding.

\section{CASE REPORT}

The patient was an infant boy born at term via Cesarean section for non-engagement following a pregnancy complicated by polyhy- draminos. The parents were non-consanguinous and there was no family history of neurological disorders. The infant was dysmorphic with microphthalmia and persistent primary vitreous, as well as hypotonic and weak with feeble suck and depressed tendon reflexes. The initial serum CK was $2,431 \mathrm{IU}$ (normal < $110 \mathrm{lU}$ ) and the EMG was myopathic. Cranial CT revealed a thin, smooth cortical mantle with a DandyWalker malformation and hydrocephalus. Extensive replacement of muscle with adipose and connective tissue along with severe loss of muscle fibers was documented on biopsy of the left gastrocnemius at 6 months. An inflammatory infiltrate of lymphocytes and macrophages was also seen (Figures IA and IB) and there was variable expression of Class 1 major histocompatibility products (MHCP) in the sarcolemma (Figure 2). There was no evidence of incomplete histochemical differentiation. Eosinophils and plasma cells were not observed. No abnormal nuclear inclusions were seen on EM. Immunoreactive dystrophin was normal. At the time of death at 9 months secondary to an aspiration pneumonia, the child was microcephalic with severe hypotonia/weakness, failure to thrive and global delay. At autopsy, all muscles sampled demonstrated a severe loss of muscle fibers without inflammation (Figure 3). Postmortem examination of the brain and eyes was refused.

\section{DisCuSSION}

With CT scan evidence for lissencephaly combined with cerebellar malformation (Dandy-Walker), persistent primary vitreous and dystrophic changes of muscle. our case clearly fulfills the most recently published criteria for the diagnosis of Walker-Warburg syndrome. ${ }^{17}$ Most intriguing is the muscle biopsy at 6 months that documents an inflammatory infiltrate

From the Division of Pediatric Neurology, Montreal Children's Hospital; and Departments of Neurology/Neurosurgery \& Pediatrics, McGill University, Montreal

Received March 24, 1992. Accepted in final form March 31, 1993

Reprint requests to: Michael Shevell. M.D., A-514, Montreal Children's Hospital, 2300 Tupper, Montreal. Quebec, Canada H3H IP3 


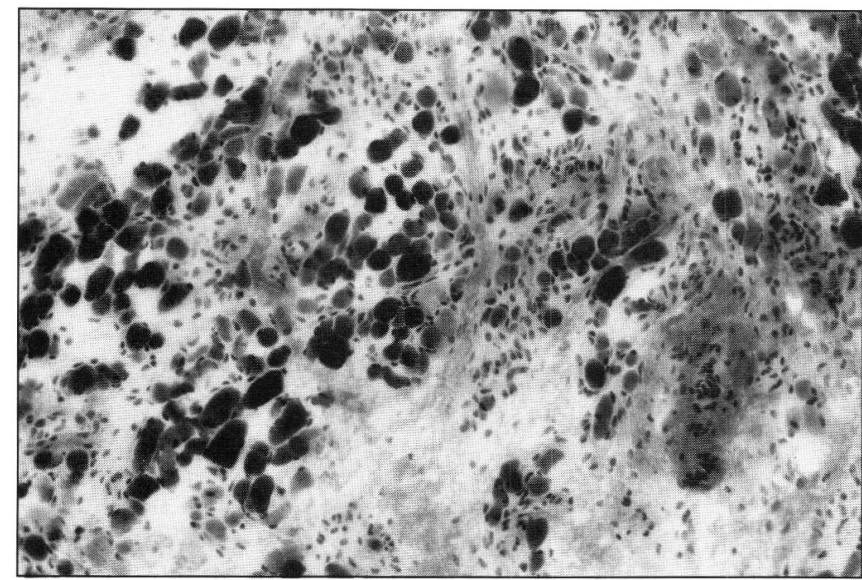

Figure IA-Muscle biopsy at 6 months shows widespread patchy loss of muscle cells with numerous mononuclear cells within fasicles. Modified trichrome, XI35.

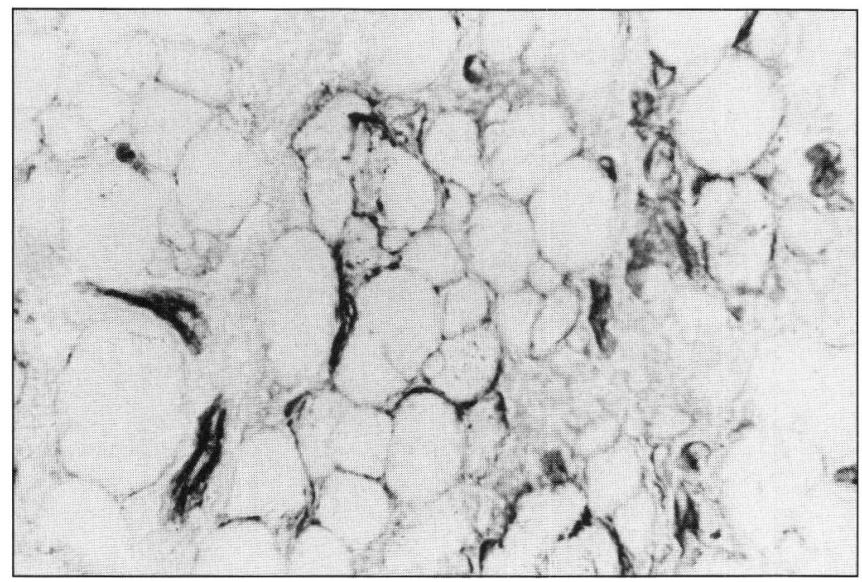

Figure 2 - Diffuse sarcolemmal expression of immunoreactive Class I major histocompatibility products (MHCP). Immunoperoxidase using a monoclonal antibody against human Class I MHCP and the biotinstreptavidin display system. X550.

and sarcolemmal expression of immunoreactive Class I MHCP. Their expression on the outer surface of muscle cells is considered to be an essential precondition for the cytolytic action of cytotoxic lymphocytes and is a consistent feature of a variety of inflammatory myopathies. ${ }^{19}$ It has proved especially valuable in those instances in which inflammation is not histologically marked. ${ }^{19}$

The first reports of muscle pathology in a Walker-Warburg syndrome equivalent was provided by Santavuori ${ }^{10}$ and further documented in a number of different reports. 9.11-17.20-22 $^{-1}$ Invariably a congenital muscular dytrophy characterized by widespread loss and degeneration of muscle fibers with resulting variation in fiber size and perimysial/endomysial fibrosis is seen. ${ }^{2 l}$ When adequately evaluated with serum CK, electromyography and muscle biopsy, abnormalities consistent with congenital muscular dystrophy are a constant feature of the WalkerWarburg phenotype. ${ }^{17.23}$ Occasional inflammatory infiltrates have been noted previously but not commented upon. ${ }^{17}$

With reports of parental consanguinity $8,18,24$ and multiple affected siblings of both sexes, ${ }^{2.3 .5 .7 .11-15.18 .20 .25}$ the preponderance

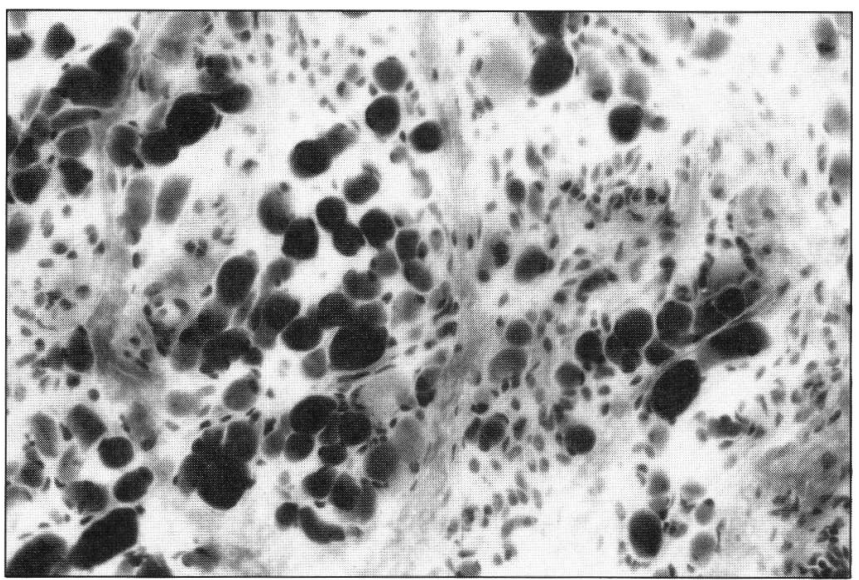

Figure IB - Higher power view showing detail of central portion of Figure IA. Modified urichrome, X230.

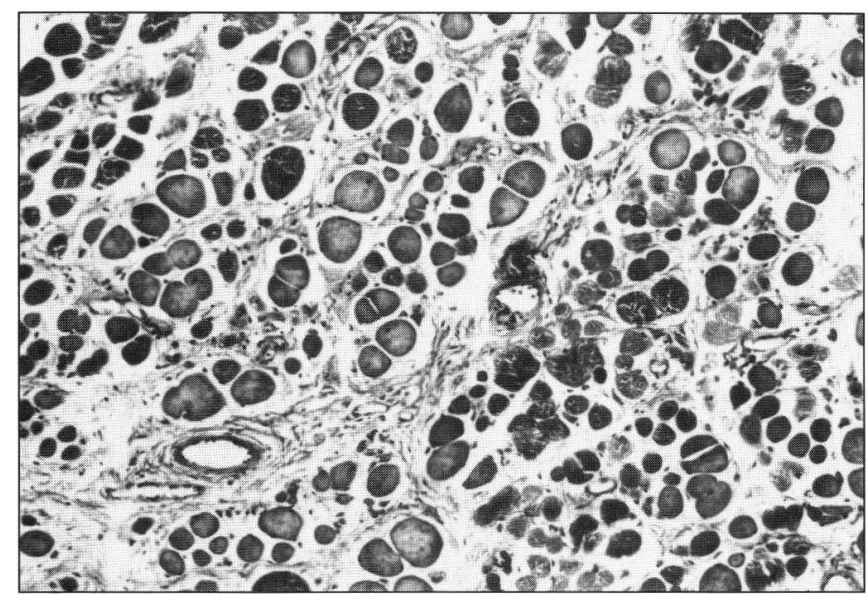

Figure 3-Skeletal muscle at autopsy show's reduced numbers of mus. cle fibers, marked variation in size, and increased endomysial connective tissue. Inflammation was rare and limited to the epimysium. Paraffin section, Hematoxylin-eosin. X350.

of evidence suggests a genetic basis for this syndrome that is inherited in an autosomal recessive fashion. ${ }^{17}$ However, several pathological studies have documented the potential role for an infectious or inflammatory etiology. Chan and colleagues' ${ }^{1}$ felt that a protracted destructive process beginning prior to the fourth month of gestation could account for the widespread ocular and cortical malformations observed that appear to be the result of some process acting upon successive developmental fields. Furthermore, Williams et al. ${ }^{9}$ suggested that a chronic meningioencephalitis, active during the second trimester, could best explain the neuropathologic findings. While another lissencephaly syndrome, Miller-Diecker, has a well established genetic basis with an underlying chromosomal deletion, ${ }^{26}$ a recent report has linked some cases of lissencephaly with congenital CMV infection. ${ }^{27}$ Thus both hypotheses regarding causation are plausible.

Our finding of an inflammatory myopathy provides initial support for the infectious/inflammatory point of view. A possible etiology for the inflammatory myopathy is an intrauterine infection that triggers muscle fiber necrosis or an immune response that cross reacts with muscle. ${ }^{28}$ Further analysis suggests that a 
more conciliatory blended view is probable. Another possibility for the inflammatory myopathy is that an alteration in muscle antigens or immunoregulatory mechanisms (maternal or fetal) could trigger an autoimmune destructive process that results in widespread inflammation. ${ }^{29}$ Clearly both susceptibility to an infectious agent or immunoregulatory control elements are under genetic influences. Thus genetic and inflammatory suppositions to explain the Walker-Warburg syndrome are not mutually exclusive but likely interactive. A final position is to suppose that genetic and inflammatory phenocopies for Walker-Warburg syndrome may exist. ${ }^{30}$ In this context it should be noted that muscle biopsies in facioscapulohumeral dystrophy, a disorder with a well established genetic basis, may show inflammatory infiltrates (macrophages). ${ }^{31}$

Congenital inflammatory myopathy, of which our patient is an example, is a heterogeneous clinical entity that is distinct from infantile myositis. ${ }^{32}$ Of interest, four patients with congenital inflammatory myopathy were also felt to have sufficient criteria for the diagnosis of Fukuyama's congenital muscular dystrophy. ${ }^{32}$ Fukuyama's syndrome, which also features Type II lissencephaly, ressembles the Walker-Warburg phenotype and is distinguished from it by the latter's greater severity of brain and ocular manifestations. ${ }^{17.33}$ It is not yet clear if these disorders are distinctly different entities or different alleles. It is interesting to note a parallel controversy exists between infectious and genetic influences in the etiology of Fukuyama's.

Neither the findings of inflammation nor the familial occurrence of these syndromes can be ignored. Theories of pathogenesis must explain both of these observations in order to be wholly correct, thus providing directions for future investigation into understanding this syndrome.

\section{ACKNOWLEDGEMENTS}

The authors would like to acknowledge the assistance of Dr. Stirling Carpenter and Dr. George Karpati of the Montreal Neurological Institute in both the interpretation of the muscle specimens and the preparation of this manuscript.

\section{REFERENCES}

1. Chan CC, Egbert PR, Herrick MK, Urich H. Oculocerebral malformations: a reappraisal of Walker's lissencephaly. Arch Neurol 1980; 37: 104-108

2. Borbardier C, Aicardi J, Goutieres F. Congenital hydrocephalus and eye abnormalities with severe developmental brain defects: Warburg's syndrome. Ann Neurol 1984; 16: 60-65.

3. Pagon RA, Clarren SK, Milam DF, Jr, Hendrickson AE. Autosomal recessive eye and brain anomalies: Warburg syndrome. J Pediatr 1983; 102: 542-546.

4. Whitley CB, Thompson TR, Mastri AR, Gorlin RG. Warburg syndrome: lethal neurodysplasia with autosomal recessive inheritance. J Pediatr 1983; 102: 547-551.

5. Pagon RA, Chandler JW, Collie WR, Clarren SK, Moon J, et al. Hydrocephalus, agyria, retinal dysplasia, encephalocele (HARD+/-E) syndrome: an autosomal recessive condition. Birth Defects 1978; 14(6B): 233-241.

6. Winter RM, Garner A. Hydrocephalus, agyria, pseudoencephalocele, retinal dysplasia and anterior chamber anomalies. J Med Genet 1981; 18: 314-317.

7. Ayme S, Mattei JF. HARD(+/-E) syndrome: report of a sixth family with support for autosomal recessive inheritance. Am J Med Genet 1983; 14: 759-766.

8. Donnai D, Farndon PA. Walker-Warburg syndrome (Warburg syndrome, HARD +/-E syndrome). J Med Genet 1986; 23: 200-203.
9. Williams RS, Swisher $C N$, Jennings $M$, Ambler M, Caviness VS, Jr. Cerebro-ocular dysgenesis (Walker-Warburg syndrome): neuropathologic and etiologic analysis. Neurology 1984; 34: 1531-1541.

10. Santavuori P, Leisti J, Kruus S. Muscle, eye and brain disease: a new syndrome. Neuropadiatrie 1977; 8: 553-558.

11. Raitta C, Lamminen M, Santavuori P, Leisti J. Ophthalmological findings in a new syndrome with muscle, eye and brain involvement. Acta Ophthalmol 1978; 56: 465-472.

12. Korinthenberg R, Palm D, Schlake W, Klein J. Congenital muscular dystrophy, brain malformation and ocular problems (muscle, eye and brain disease) in two German families. Eur J Pediatr 1984; 142: 64-68.

13. Towfighi J, Sassani JW, Suzuki K, Ladda RL. Cerebro-ocular dysplasia-Muscular dystrophy (COD-MD) syndrome. Acta Neuropathol 1984; 65: 110-123.

14. Heggie P, Grossniklaus HE, Roessmann U, Chou SM, Cruse RP. Cerebro-ocular dysplasia-muscular dystrophy syndrome: report of two cases. Arch Ophthalmol 1987; 105: 520-524.

15. Dambska M, Wisniewski K, Sher J, Solish G. Cerebro-oculo-muscular syndrome: a variant of Fukuyama congenital cerebromuscular dystrophy. Clin Neuropathol 1982; 1: 93-98.

16. Heyer R, Ehrich J, Goebel HH, Christen HJ, Hanefield F. Congenital muscular dystrophy with cerebral and ocular malformations (cerebro-oculo-muscular syndrome). Brain Dev 1986; 8: 614-619.

17. Dobyn WB, Pagon RA, Armstrong D, Curry CJR, Greenberg F, et al. Diagnostic criteria for Walker-Warburg syndrome. Am J Med Genet 1989; 32: 195-210.

18. Chemke J, Czernobilsky B, Mundel G, Barishak YR. A familial syndrome of central nervous system and ocular malformation. Clin Genet 1975; 7: 1-7.

19. Karpati G, Pouliot Y, Carpenter S. Expression of immunoreactive histocompatability complex products in human skeletal muscles. Ann Neurol 1988; 23: 64-72.

20. Pavone L, Gullotta F, Grasso S, Vannucchi C. Hydrocephalus, lissencephaly, ocular abnormalities and congenital muscular dystrophy. A Walker syndrome variant? Neuropediatrics 1986; 17 : 206-211.

21. Takada K, Becket LE, Takashima S. Walker-Warburg syndrome with skeletal muscle involvement: a report of three patients. Pediatr Neurosci 1987; 13: 202-209.

22. Weinberg AG. Walker Warburg syndrome. Pediatr Pathol 1989; 9: $749-755$.

23. Dobyns WB, Pagon RA, Armstrong D, Curry CJR, Greenburg F, et al. New diagnostic criteria for Walker-Warburg syndrome [Abstract]. Am J Hum Genet 1986; 39: A59.

24. Warburg M. Hydrocephaly, congenital retinal nonattachment and congenital falciform fold. Am J Ophthamol 1978; 85: 88-94.

25. Dobyns WB, Kirkpatrick JB, Hittner HM, Roberts RM, Kretzer FL. Syndromes with lissencephaly II: Walker-Warburg and cerebrooculo-muscular syndromes and a new syndrome with type II lissencephaly. Am J Med Genet 1985; 22: 157-195.

26. Dobyns WB, Curry CJR, Hoyme HE, Turlington L, Ledbetter DH. Clinical and molecular diagnosis of Miller-Dieker syndrome. Am J Hum Genet 1991; 48: 584-594.

27. Hayward JC, Titelbaum DS, Clancy RR, Zimmerman RA. Lissencephaly-pachygyria associated with congenital cytomegalovirus infection. J Child Neurol 1991; 6: 109-114.

28. Whitaker JN. Inflammatory myopathy: a review of etiologic and pathogenetic factors. Muscle Nerve 1982; 5: 573-592.

29. Mastaglia FL, Ojeda VJ. Inflammatory myopathies: Part I. Ann Neurol 1985; 17: 215-227.

30. Williams RS, Caviness VS, Jr. Walker-Warburg syndrome [Letter] Neurology 1985; 35: 1082-1083.

31. Carpenter S, Karpati G. Pathology of Skeletal Muscle. New York: Churchill Livingstone 1984: 507-510.

32. Shevell M, Rosenblatt B, Silver K, Carpenter S, Karpati G. Congenital inflammatory myopathy. Neurology 1990; 40: 1111. 1114.

33. Gordon N. Muscle and brain disease. Dev Med Child Neurol 1988 30: $546-549$. 